\title{
SCIDiC
}

\author{
International Journal of Dentistry and Oral Science (IJDOS) \\ ISSN: 2377-8075
}

\section{Development Of Anti Inflammatory and Antimicrobial Silver Nanoparticles Coated Suture Materials}

Research Article

Jembulingam Sabarathinam ${ }^{1}$, Madhulaxmi $^{*}$, Rajeshkumar ${ }^{3}$

${ }^{1}$ Professor Department of Oral \& Maxillofacial Surgery Saveetha Dental College \& Hospitals Saveetha Institute Of Medical \& Technical Sciences Saveetha University, Chennai 600077, India.

${ }^{2}$ Saveetha Dental College \& Hospitals Saveetha Institute Of Medical \& Technical Sciences (SIMATS) Saveetha University, Chennai 600077, India.

${ }^{3}$ Associate Professor Department of Pharmacology, Saveetha Dental College and Hospitals, Saveetha Institute of Medical and Technical Sciences, Saveetha University, Chennai-600077, Tamil Nadu, India.

\section{Abstract}

Background: Sutures are biomechanical devices used in oral surgery to avoid or limit the exposure of those parts exposed to saliva from bacterial colonization. Nanotechnology witnessed tremendous growth and became an integral part of medical sciences because of its wide range of application in different principles of diagnosis and treatment of various diseases. There has been an expeditious advance in medicines and biomaterial in the recent years. Nanomedicine aids in prevention, diagnosis, monitoring and treatment of the diseases.

Aim: The aim of the current study was to synthesize biogenic silver nanoparticles using Solanum nigrumand Indigofera tinctoria as reducing agents and assess the antimicrobial, anti-inflammatory and the cytotoxic properties of the biogenic silver nanoparticles. Further the study also aims to analyse the application of biogenic silver nanoparticles coated on surgical sutures. Materials and Methods: In this report, we used the extract of Solanum nigrum and Indigofera tinctoria to synthesize silver nanoparticles and were characterized using UV-visible spectrophotometer, SEM and TEM. These nanoparticles were subjected to anti-inflammatory, Anti-microbial and and cytotoxic assays. Further these nanoparticles synthesized were coated on surgical silk sutures and subjected to antimicrobial assay.

Results: The formed nanoparticles inherited important antibacterial properties against Pseudomonas sp, streptococcus mutan and staphylococcus aureus. They also possess anti inflammatory activity and also prove to be biocompatible.

Conclusion: This break through in the field of surgical biomaterial may help reduce the toxic effects of pathogenic organisms while representing an environmentally friendly material which would not only be economically efficient but also proves to be a material with minimal risk to mankind and the environment.

Keywords: Dentistry; Antimicrobial; Suture Materials; Anti-Inflammatory; Biocompatible; Silk.

\section{Introduction}

In the past decade, nanotechnology witnessed tremendous growth and became an integral part of medical sciences because of its wide range of application in different principles of diagnosis and treatment of various diseases [1]. There has been an expeditious advance in medicines and biomaterial in the recent years [2]. Nanomedicine aids in prevention, diagnosis, monitoring and treatment of the diseases. Silver Nanoparticles have always been the nanoparticle of choice in modern medicine due their significantly proven antimicrobial activity. Henceforth they play a critical role in the development of modern science, especially in the biological systems [3-8].

It is a well established fact that the size and shape determines the properties of the silver nanoparticles. Moreover, their controllable

\section{*Corresponding Author:}

Madhulaxmi,

Professor Department of Oral \& Maxillofacial Surgery Saveetha Dental College \& Hospitals Saveetha Institute Of Medical \& Technical Sciences Saveetha University, Chennai 600077, India.

Tel: 7373814000

Email Id: madhulaxmi@saveetha.com

Received: February 082021

Accepted: March 03, 2021

Published: March 17, 2021

Citation: Jembulingam Sabarathinam, Madhulaxmi, Rajeshkumar. Development Of Anti Inflammatory and Antimicrobial Silver Nanoparticles Coated Suture Materials. Int J Dentistry Oral Sci. 2021;08(03):2006-2013. doi: http://dx.doi.org/10.19070/2377-8075-21000395

Copyright: MadhulaxmiO2021. This is an open-access article distributed under the terms of the Creative Commons Attribution License, which permits unrestricted use, distribution and reproduction in any medium, provided the original author and source are credited. 
synthesis proves to be a key challenge to acquire more desirable characteristics [9]. Traditionally synthesized nanoparticles have adverse side effects upon administration due to the highly toxic chemicals which are being used for their synthesis [10]. Hence, an alternative method of synthesis is required to overcome these adverse effects of the nanoparticles.

Green chemistry suggests that there is a need for the majority of the industries to become more sustainable through developing eco-friendly products $[11,12]$. Green chemistry offers alternative approaches for synthesis of nanoparticles, by incorporating plant extracts as they can be used to generate biogenic nanoparticles $[13,14]$.

Solanum nigrum belongs to the solanaceae family, commonly addressed as the makoi or blacknight shade. It is referred to as Manathakkali in Tamil. S.Nigrum has been used for treatment of fever, inflammation and stomach ulcers in Ayurveda (Traditional medicine of India) [15]. It exhibits medicinal properties such as antimicrobial activity, antioxidant activity, cytotoxic properties, diuretic property, antiulcerogenic and hepatoprotective properties. It is reported to be an alternative potential anti-cancer drug $[16,17]$.

Indigofera tinctoria belongs to the family of Indirubins (bis-indoles), commonly addressed as indigo plants. It is referred to as avuri in Tamil. This plant is commonly cultivated in India and china. This herb is widely used in indian system of medicine for epilepsy, nervous disorder, bronchitis, and liver ailments.- Few literature studies also reported that the herb can be used as an anticardiovascular agent $[18,19]$.

Suture are biomechanical devices used in oral surgery to avoid or limit the exposure of those parts exposed to saliva from bacterial colonization [20]. Regardless, they offer adhesion to bacteria on their surface which increases the susceptibility to postoperative infections. Moreover surgical knots are reported to be the fundamental site of bacterial colonization [21, 22]. Silk sutures have been reported as the most commonly used suture material for wound closure with acceptable results. However due to the natural fibers being used in production of the silk sutures increase the risk of development of infections [23]. Once the sutures are infected, the local mechanisms are inactivated while some pathogens are antibiotic resistant. Hence, tremendous efforts had been taken to add antiseptics such as chlorhexidine and triclosan to the sutures $[24,25]$. Though few cases have been reported to be allergic to these chemical substances [26].

Henceforth, the current study aims to synthesize biogenic silver nanoparticles using Solanum nigrum and Indigofera tinctoria as reducing agents and assess the antimicrobial, anti-inflammatory and the cytotoxic properties of the biogenic silver nanoparticles. Further the study also aims to analyse the application of biogenic silver nanoparticles coated on surgical sutures.

\section{Materials and Methods}

The herbs Solanum nigrum and Indigofera tinctoria were obtained from green chem herbal extracts, Bangalore, India. $0.5 \mathrm{~g}$ of dried S. nigrum and $0.5 \mathrm{~g}$ of dried I.tinctoria powder were transferred into $100 \mathrm{~mL}$ of double distilled water in a $250 \mathrm{ml}$ erlen- meyer flask and boiled the mixture for 15 minutes. This process extracted the components of the extracts in to water. Whatmann No 1 filter paper was used for the filtration of boiling material, to remove any suspended particles. Finally, a clear filtrate was obtained and used for metal nanoparticle synthesis.

\section{Biosynthesis Of Silver Nanoparticles (AgNPs) Using Leaf Extract $1 \mathrm{mM}$ Of AgNO3}

The aqueous extract of S. nigrum and I. tinctoria was used for the bioreduction process. For the biosynthesis of AgNPs, $20 \mathrm{~mL}$ of aqueous extract was carefully added to $80 \mathrm{~mL}$ of $1 \mathrm{mM}$ of aqueous AgNO3 solution in $250 \mathrm{~mL}$ Erlenmeyer flasks. The flasks containing the extract were incubated in an orbital shaker (FIGURE 1). The color changes in the reaction mixture was observed continuously at various periods of time by double beam UV-vis spectrophotometer at different wavelength regions from 350 to $550 \mathrm{~nm}$. The biosynthesized silver nanoparticles were centrifuged at $8000 \mathrm{rpm}$ for $10 \mathrm{~min}$ and nanoparticles were collected.

\section{Characterization Of Prepared Nanoparticles}

The synthesized nanoparticles were optically measured using double beam UV -vis spectrophotometer at different wavelength ranges of 350 to $550 \mathrm{~nm}$. Morphological characterization of prepared nanoparticles was done using Transmission Electron Microscope (TEM) and Scanning electron microscope(SEM).

\section{Antimicrobial Activity}

The silver nanoparticles synthesized using S.nigrum and I.tinctoria were tested for antimicrobial activity by agar well diffusion method against surgical site pathogens namely S. mutans, S.aureus and Pseudomonas sp. The pure culture of these bacteria was subcultured on Mueller Hinton agar. Wells of $9 \mathrm{~mm}$ diameter were made on Muller Hinton agar plates using gel puncture and each strain was uniformly swabbed on to the individual plates using sterile cotton swabs. Using a sterile micropipette, a standard antibacterial agent was loaded into one well and three different concentrations of silver nanoparticles sample solutions $(25 \mu \mathrm{l}, 50 \mu \mathrm{l}$ and $100 \mu \mathrm{l})$ were added onto three other wells on all plates. After incubation at $37^{\circ} \mathrm{C}$ for 24 hours, the different levels of zone of inhibition of bacteria were observed and measured.

\section{Cytotoxicity Essay}

Brine shrimp eggs were obtained from the Aquatic Remedies, Chennai. In this test, 6 elisa wells were filled with $2 \mathrm{~g}$ of non iodised salt dissolved in $200 \mathrm{~mL}$ of distilled water. In each well, 10 nauplii ( freshly prepared brine shrimp larvae) were transferred. Among the 6 wells, 5 wells were loaded with AgNPs in different concentrations (10 microL, 20 microL, 30 microL, 40 microL, 50 microL). The last well was used as control without any nanoparticle. Finally the wells were filled with salt water till the brim and observed for changes after 24hrs (FIGURE 2).

\section{Anti-Inflammatory Activity}

Inhibition of Protein Denaturation method (MIZUSHTMA: 1966)

Concentration Of Test Substance: $10-50 \mu \mathrm{g} / \mathrm{ml}$ 
Standard: Diclofenac sodium.

Chemicals Required: Bovine serum albumin, $1 \mathrm{NHCl}$, Phosphate buffer (pH 6.3).

Instrument: Incubator, Spectrophotometer - 660nm.

The following 4 solutions were used

1. Test Solution $(0.5 \mathrm{ml})$ consist of $0.45 \mathrm{ml}$ of bovine serum albumin $(5 \% \mathrm{w} / \mathrm{v}$ aqueous solution) and $0.05 \mathrm{ml}$ of test solution in various concentration and $\mathrm{pH}$ will be adjusted to 6.3 by using a small amount of $1 \mathrm{~N} \mathrm{Hcl}$.The samples were incubated at 370C for 20 minutes and heated at $570 \mathrm{C}$ for 3 minutes(FIGURE 3). After cooling, to the sample add $2.5 \mathrm{ml}$ of Phosphate buffer ( $\mathrm{pH}$ 6.3).

2. Test Control solution $(0.5 \mathrm{ml})$ consists of $0.45 \mathrm{ml}$ of Bovine serum albumin ( $5 \%$ aqueous solution) and $0.05 \mathrm{ml}$ of distilled water and $\mathrm{pH}$ will be adjusted to 6.3 by using a small amount of $1 \mathrm{~N} \mathrm{Hcl}$ the samples were incubated at $370 \mathrm{C}$ for 20 minutes and heated at $570 \mathrm{C}$ for 3 minutes. After cooling, to the sample add $2.5 \mathrm{ml}$ of phosphate buffer ( $\mathrm{pH}$ 6.3).

3. Product Control $(0.5 \mathrm{ml})$ consists of $0.45 \mathrm{ml}$ of distilled water and $0.05 \mathrm{ml}$ of test solution in various concentrations and $\mathrm{pH}$ will

Figure 1. Figure represents the reaction mixture placed on an orbital shaker in left and sedimentation on the biogenic nanoparticles in a cuvette on the right.

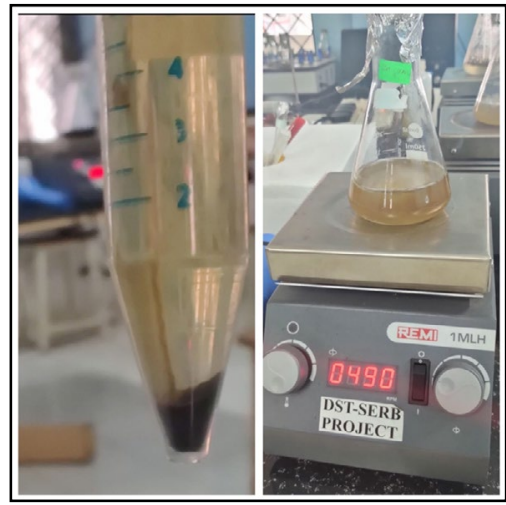

Figure 2. ELISA wells with the nauplii.

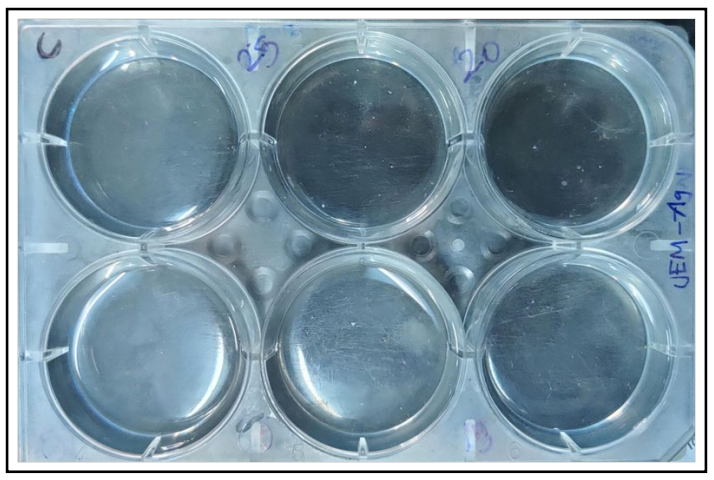

Figure 3. Incubation of the test and standard solutions after heating.

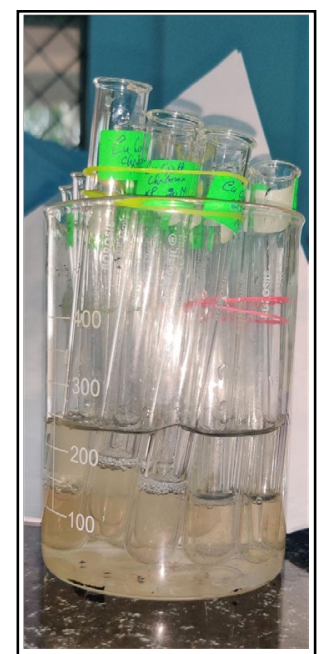


be adjusted to 6.3 by using a small amount of $1 \mathrm{~N} \mathrm{Hcl}$. The samples were incubated at $370 \mathrm{C}$ for 20 minutes and heated at $570 \mathrm{C}$ for 3 minutes. After cooling to the sample add $2.5 \mathrm{ml}$ to phosphate buffer (pH6.3).

4. Standard Solution $(0.5 \mathrm{ml})$ consists of $0.45 \mathrm{ml}$ of bovine serum albumin $(5 \% \mathrm{w} / \mathrm{v}$ aqueous solution and $0.05 \mathrm{ml}$ of diclofenac sodium solution in various concentrations and $\mathrm{pH}$ will be adjusted to 6.3 by using a small amount of $1 \mathrm{~N} \mathrm{Hcl}$. The samples were incubated at $370 \mathrm{C}$ for 20 minutes and heated at $570 \mathrm{C}$ for 3 minutes. After cooling, to the sample add $2.5 \mathrm{ml}$ of phosphate buffer (pH6.3).

The percentage inhibition of Protein denaturation was calculated as follows.

OD of test solution - OD of product control

Percent Inhibition $=100$ X 100

OD of test control

The control represents 100\% protein denaturation. The result will be compared with diclofenac sodium treated samples.

\section{Antimicrobial Efficiency Of The AgNP Coated Sutures:}

The silver nanoparticles synthesized using S. Nigrum and I. Tinctoria were coated on sutures by dipping the sutures in the nanoparticle solution and incubating for $24 \mathrm{hrs}$. Then the coated sutures were tested for antimicrobial activity by agar well diffusion method against surgical site pathogens namely S. Mutans, S. Aureus and Pseudomonas sp sp. The pure culture of these bacteria was subcultured on Mueller Hinton agar. Each strain was uniformly swabbed onto the individual plates using sterile cotton swabs and the sutures were embedded. After incubation at $37^{\circ} \mathrm{C}$ for 24 hours, the different levels of zone of inhibition of bacteria were observed and measured.

\section{Results}

\section{Visual Analysis:}

The present study reveals about the silver nanoparticles synthesized using the herbs Solanum nigrum and Indigofera tinctoria as bioreducing agents. The colour change in the reaction mixture was observed continuously at various periods of incubation time. The silver nitrate was reduced to silver nanoparticles, which was visually indicated by colour change. The colour of the solution changed from little green to dark brown in 24 hours. The intensity of the colour change gradually increased during the incubation period. There was no colour change after 48 hours indicating that the silver nanoparticle synthesis was completed.(FIGURE 4).

\section{UV vis Spectrophotometer Analysis:}

UV vis spectroscopy analysis depends on the arising of colour in the reaction, due to excitation of surface plasmon resonance band in the reaction mixture between different wavelengths from 350 to $550 \mathrm{~nm}$ and was recorded. Figure 2 shows the UV absorbance spectra of the synthesized silver nanoparticles using the extract of the herbs Solanum nigrumand Indigofera tinctoria.

The figure depicts a steady increase in absorbance over the incubation time period. The plasmon resonance band was peak in 365nm (FIGURE 5).

\section{Transmission Electron Microscopy:}

The structure of the AgNPs synthesized using the herbs Solanum nigrum and Indigofera tinctoria as bioreducting agents are mostly spherical and hexagonal in shape. The morphology of the silver nanoparticles were highly variable with size range of $10-35 \mathrm{~nm}$ (FIGURE 6).

Figure 4. Colour change of the reaction over the period of incubation time of 48 hours.

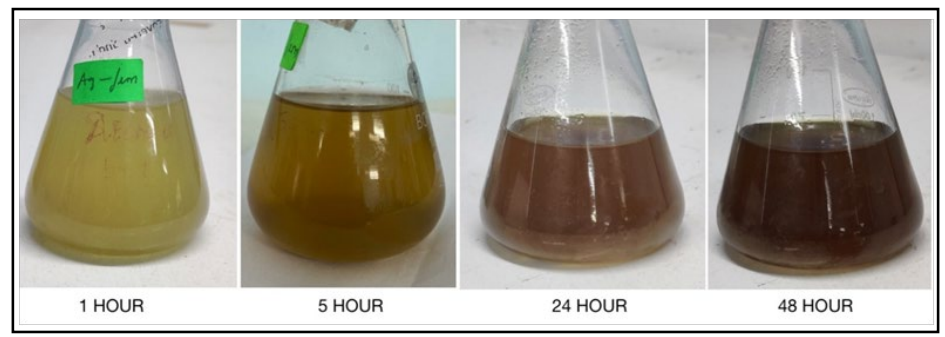

Figure 5. Graph of absorbance acquired from the UV vis spectrophotometry. The $x$ axis represents the wavelength of while the $\mathrm{Y}$ axis represents the absorbance.

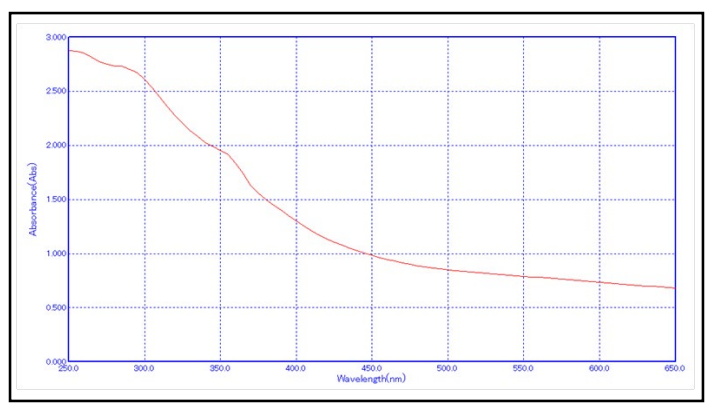




\section{Scanning Electron Microscopy:}

SEM analysis of the structure of the AgNPs synthesized using the herbs Solanum nigrum and Indigofera tinctoria as bioreducting agents are mostly spherical and elliptical in shape (FIGURE 7).

\section{Anti-Inflammatory Activity:}

The biogenic silver nanoparticles show comparable anti-inflammatory activity with standard diclofenac sodium which is a chemical analgesic at 50 microL concentration (Figure 3). The Biogenic silver nanoparticles can act as a potent anti-inflammatory Drug (FIGURE 8).

\section{Antimicrobial Activity:}

The antimicrobial activity of the biogenic silver nanoparticles assayed by well diffusion method against surgical site pathogen showed minimum inhibitory concentrations at various concentrations. The antimicrobial activity increases with increase in concentration. The antimicrobial activity was evaluated by comparing the zone of inhibition of the AgNPs to standard antibiotics(FIGURE 9). The antibacterial activity of AgNPs against Pseudomonas sp was highest at 150 microL with zone of inhibition measuring $17.6 \mathrm{~mm}$ while S. Aureus and S. Mutan showed zone of inhibition measuring $12.8 \mathrm{~mm}$ and $11 \mathrm{~mm}$ respectively (FIGURE 10,11,12).

\section{Cytotoxic Activity:}

The cytotoxic activity of these biogenic AgNPs were very less, indicating that they are biocompatible. At 50 microL concentration, there was $10 \%$ morality when the lethality assay was performed.

The antimicrobial activity of the biogenic silver nanoparticles coated silk sutures assayed by well diffusion method against surgical site pathogen showed zones of inhibition for different bacterias. The zone of inhibition around the suture was $5 \mathrm{~mm}$ when subjected to Pseudomonas sp. While the zone of inhibition was

Figure 6. Biogenic silver nanoparticles under transmission electron microscope (TEM analysis).

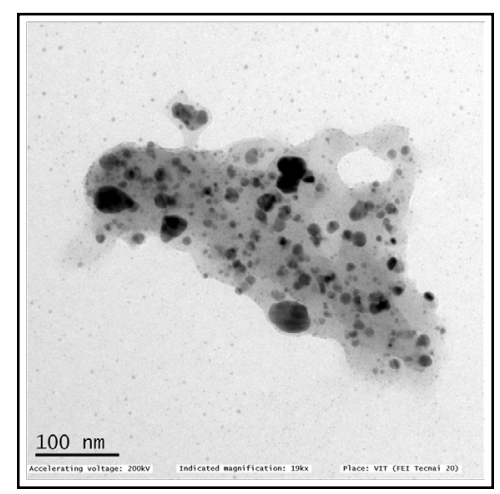

Figure 7. Biogenic silver nanoparticles under Scanning electron microscope (TEM analysis).

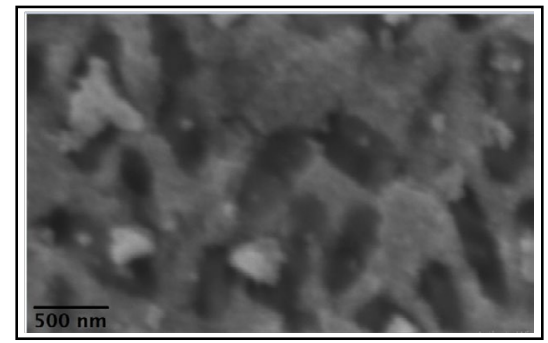

Figure 8. Bar graph depicts the anti-inflammatory activity of biogenic silver nanoparticle; $\mathrm{X}$ axis represent the concentrations of samples; $\mathrm{Y}$ axis denotes the inhibition percentage; red colour denotes the silver nanoparticles and yellow colour represents the standard antiinflammatory agent (Control).

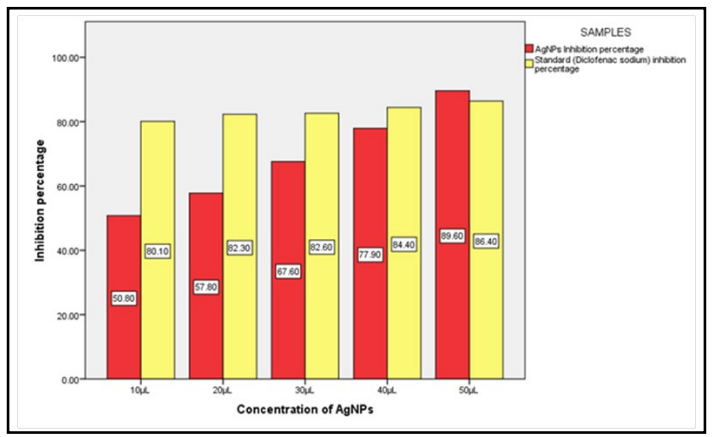


$6 \mathrm{~mm}$ against $\mathrm{S}$. Mutans and $5 \mathrm{~mm}$ against S. Aureus (FIGURE 11). There was no zone of inhibition identified around the Control Group (suture with no coating). This was statistically significant with $\mathrm{p}$ value -0.000 .

\section{Discussion}

Foreign suture materials are a source of infection, as bacteria gets lodged on to the suture material used when periodontal and oral surgical procedures are performed [20]. Sutures are always placed in areas with high vascular supply to promote healing, which is also a moist bacteria rich environment. When natural, multi braided sutures such as silk are used, they increase the risk of infection as bacteria gets retained in the interstices. Thus the choice of selection of the type of suture used proves to be a critical factor in deciding the level of risk of infection. The use of monofilament sutures composed of animal intestines are being restricted in the European countries and Japan due to the allergic reaction caused by them $[22,27]$. One the other hand, the silk sutures made of natural fibers absorb more water and favour bacterial colonization

Figure 9. Antimicrobial activity of biogenic silver nanoparticles by agar well diffusion method against surgical site pathogens namely S. mutans, S.aureus and Pseudomonas sp.

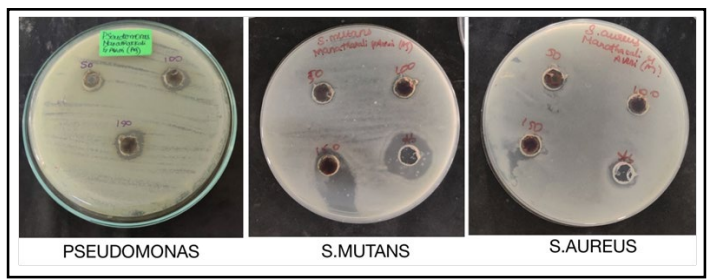

Figure 10. Bar graph depicts the measurement of zone of inhibition of biogenic silver nanoparticle; $Y$ axis represent the measurement of zone of inhibition; $X$ axis denotes the specific organisms;

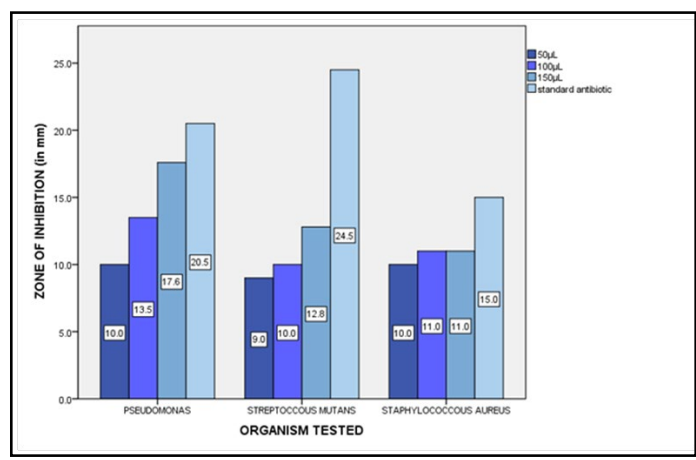

Figure 11. Bar graph depicts the cytotoxic activity of Biogenic silver nanoparticles; Y axis represent the frequency of nauplii alive; $\mathrm{X}$ axis denotes the concentration of nanoparticles.

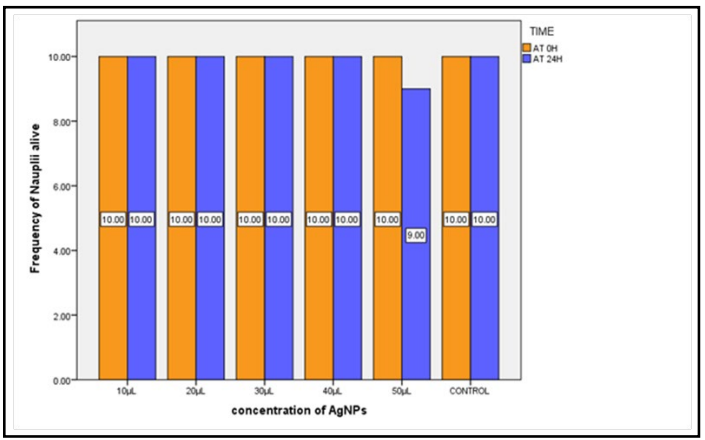

Figure 12. Antimicrobial activity of biogenic silver nanoparticle coated silk suture by agar well diffusion method against surgical site pathogens namely S. Mutans, S.Aureus and Pseudomonas species.

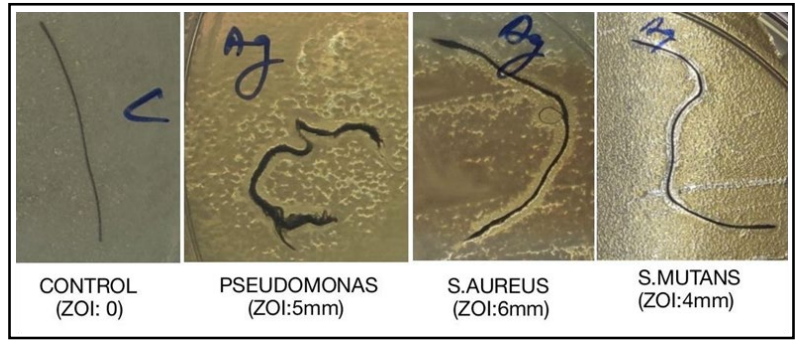


Figure 13. Bar graph depicts the measurement of zone of inhibition of biogenic silver nanoparticle coated silk sutures; $Y$ axis represent the measurement of zone of inhibition; $X$ axis denotes the specific organisms;

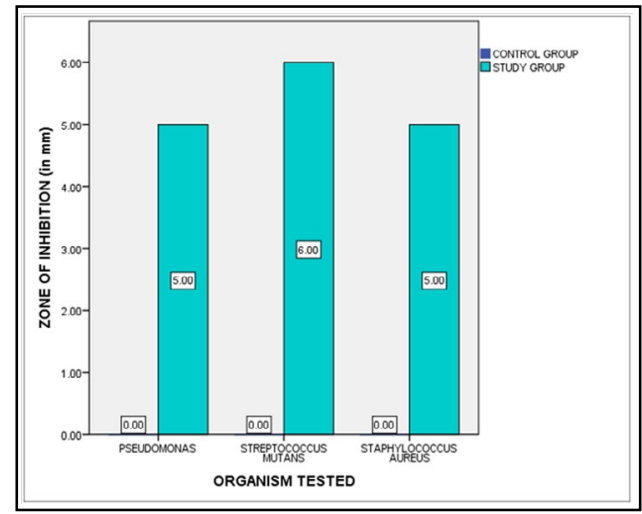

[23]. Even though both the natural sutures have good biocompatibility, less tissue reaction and better flexibility, surgeons prefer the use of synthetic sutures which does not favour the growth of bacterial colonies on their surface [28]. We believe that use of bionanocomposite coated silk sutures can reduce the colonization of pathogenic organisms. In our current study, silver was chosen as a non-toxic, safe inorganic antibacterial agent that has been reported to have inhibited more than 650 types of disease causing pathogens [24]. Moreover, silver nanoparticles have also been reported to inhibit bacterial colonization.

Although many studies have been conducted to evaluate the effectiveness of silver nanoparticles, their mechanism of action is not completely understood. It is believed that the interaction of the negatively charged bacterial cells and the positively charged nanoparticles is responsible for the antibacterial activity of the nanoparticles [29]. AgNPs can break the disulphide bonds of the protein of the bacteria thereby producing an antimicrobial effect on a wide range of gram positive and gram negative bacteria. Studies performed by Dakal et al and Wanj et al had reported that the AgNPs neutralizes the surface electric charge of the bacterial membrane leading to the leakage of the cell contents and ultimately the death of the bacteria $[30,31]$. The size of the nanoparticles are comparatively very small compared to the bacterial cell which increases the chance of interaction with the bacteria more frequently. The size and shape of the nanoparticles are of great importance as they can be altered to provide desirable results [10].

The development of eco-friendly processes for synthesis of nanoparticles is a crucial factor in the field of nanotechnology [32]. The green synthesis of nanoparticles using eco friendly agents can make an environmentally and economically stable method which can be cost efficient and can have additional combined efforts of the herbs such as Solanum nigrum and Indigofera tinctoria. It has been reported that these herbs possess antimicrobial activity, antioxidant activity, cytotoxic properties, diuretic property, antiulcerogenic, anti inflammatory and hepatoprotective properties. Significantly many components of these herbs have been utilized for bioreduction and formation of nanoparticles [15-20].

Studies performed by Sarai et al, have reported that the silver nanoparticles produced by using the herb Chenopodium ambrosioides as bioreducing agent has antimicrobial properties which can be coated on sutures to reduce bacterial load on the surgical site post operatively. Though the previous study has not men- tioned the cytotoxic properties of the nanoparticles and its herb availability [33]. Our current study has been conducted with abundantly available herbs, Solanum nigrum and Indigofera tinctoria in the indian soil. Our current study has also demonstrated about the anti inflammatory and cytotoxic properties of the same nanoparticles synthesis by green chemistry and validates its application in the field of oral surgery on sutures.

The increased surface area to volume ratio has favoured the AgNPs to be effice in small quantities [34]. Henceforth, we contemplate the use of biogenic nanoparticles as an alternative approach to battle the bacterial resistance towards conventional antibiotics [35-40]. Conventional antibiotics have to be used in minimal proportion as exaggerated prescription of antibiotics would affect the systemic health of the patient. Further in vivo studies have to be performed in future to market the product in the current scenario.

\section{Conclusion}

Aseptic field is considered as the most important pillar of oral surgery and oral surgical procedure and it is essential to implement all means to achieve it. The biogenic silver nanoparticles present here can be a useful tool against the resistance bacteria and to battle antibiotic resistance. The biogenic silver nanoparticles synthesised with help of combined bioreducing agents such as Solanum nigrum and Indigofera tinctoria turned out to be the most appropriate reducing agent to coat the surgical silk sutures with AgNPs. The formed nanoparticles inherited important antibacterial properties against Pseudomonas sp, streptococcus mutan and staphylococcus aureus. They also possess antiinflammatory activity and also prove to be biocompatible. This breakthrough in the field of surgical biomaterial may help reduce the toxic effects of pathogenic organisms while representing an environmentally friendly material which would not only be economically efficient but also proves to be a material with minimal risk to mankind and the environment.

\section{References}

[1]. Faramarzi MA, Sadighi A. Insights into biogenic and chemical production of inorganic nanomaterials and nanostructures. Adv Colloid Interface Sci. 2013 Mar;189-190:1-20. Pubmed PMID: 23332127.

[2]. Naqvi SZ, Kiran U, Ali MI, Jamal A, Hameed A, Ahmed S, et al. Combined efficacy of biologically synthesized silver nanoparticles and different antibiotics against multidrug-resistant bacteria. Int J Nanomedicine. 2013;8:3187- 
95. Pubmed PMID: 23986635.

[3]. Coccia M, Wang L. Path-breaking directions of nanotechnology-based chemotherapy andmolecular cancer therapy. Technological Forecasting and Social Change. 2015;94:155-169.

[4]. Falzarano MS, Flesia C, Cavalli R, Guiot C, Ferlini A. Nanodiagnostics and Nanodelivery Applications in Genetic Alterations. Curr Pharm Des. 2018;24(15):1717-1726. Pubmed PMID: 29318963.

[5]. Ibrahim HMM. Green synthesis and characterization of silver nanoparticles using bananapeel extract and their antimicrobial activity against representative microorganisms.258 Silver Nanoparticles - Fabrication, Characterization and Applications,Journal of Radiation Research and Applied Sciences. 2015;8:265-275.

[6]. Beyth N, Houri-Haddad Y, Domb A, Khan W, Hazan R. Alternative antimicrobial approach: nano-antimicrobial materials. Evid Based Complement Alternat Med. 2015;2015:246012. Pubmed PMID: 25861355.

[7]. Najafi-Taher R, Ghaemi B, Kharrazi S, Rasoulikoohi S, Amani A. Promising Antibacterial Effects of Silver Nanoparticle-Loaded Tea Tree Oil Nanoemulsion: a Synergistic Combination Against Resistance Threat. AAPS PharmSciTech. 2018 Apr;19(3):1133-1140. Erratum in: AAPS PharmSciTech. 2018 Jan 11; Pubmed PMID: 29218583.

[8]. Kora AJ, Sashidhar RB. Biogenic silver nanoparticles synthesized with rhamnogalacturonan gum: antibacterial activity, cytotoxicity and its mode of action. Arab. J. Chem. 2018 Mar 1;11(3):313-23.

[9]. Shinde NM, Lokhande AC, Lokhande CD. A green synthesis method for large area silver thin film containing nanoparticles. J Photochem Photobiol B. 2014 Jul 5;136:19-25.Pubmed PMID: 24836517.

[10]. Roy N, Gaur A, Jain A, Bhattacharya S, Rani V. Green synthesis of silver nanoparticles: an approach to overcome toxicity. Environ. Toxicol. Pharmacol. 2013 Nov 1;36(3):807-12.

[11]. Bindhu MR, Umadevi M. Antibacterial and catalytic activities of green synthesized silver nanoparticles. Spectrochim Acta A Mol Biomol Spectrosc. 2015 Jan 25;135:373-8.

[12]. Anastas P. Green Chemistry: Theory and Practice. Oxford University Press; 2000. 135 p.ISBN: 9780198506980

[13]. Hoskote Anand KK, Mandal BK. Activity study of biogenic spherical silver nanoparticles towards microbes and oxidants. Spectrochim Acta A Mol Biomol Spectrosc. 2015 Jan 25;135:639-45.Pubmed PMID: 25128676

[14]. Liu L, Liu T, Tade M, Wang S, Li X, Liu S. Less is more, greener microbial synthesis of silver nanoparticles. Enzyme Microb. Technol. 2014 Dec $1 ; 67: 53-8$.

[15]. Jain R, Sharma A, Gupta S, Sarethy IP, Gabrani R. Solanum nigrum: current perspectives on therapeutic properties. Altern Med Rev. 2011 Mar;16(1):7885.Pubmed PMID: 21438649.

[16]. Mohy-Ud-Din A, Khan ZU, Ahmad M, Kashmiri MA. Chemotaxonomic value of alkaloids in Solanum nigrum complex. Pak.J.Bot. 2010 Jan 1;42(1):653-60.

[17]. Singh K, Aali NS, Khan MI, Ahirwar V. Effect of Solanum nigrum on protein content of liver and kidney of albino rats. Pharm Globale (IJCP). $2011 ; 4(8): 1-3$

[18]. Singh B, Saxena AK, Chandan BK, Bhardwaj V, Gupta VN, Suri OP, et al. Hepatoprotective activity of indigtone--a bioactive fraction from Indigofera tinctoria Linn. Phytother Res. 2001 Jun;15(4):294-329.Pubmed PMID: 11406850

[19]. Narender T, Khaliq T, Puri A, Chander R. Antidyslipidemic activity of furano-flavonoids isolated from Indigofera tinctoria. Bioorg Med Chem Lett. 2006 Jul 1;16(13):3411-4.Pubmed PMID: 16644212.

[20]. Banche G, Roana J, Mandras N, Amasio M, Gallesio C, Allizond V, et al. Microbial adherence on various intraoral suture materials in patients undergoing dental surgery. J Oral Maxillofac Surg. 2007 Aug;65(8):1503-7. Pubmed PMID: 17656275

[21]. Leknes KN, Selvig KA, Bøe OE, Wikesjö UM. Tissue reactions to sutures in the presence and absence of anti-infective therapy. J Clin Periodontol. 2005 Feb;32(2):130-8.Pubmed PMID: 15691341.

[22]. Niaounakis M. Biopolymers: Applications and Trends. Plastics Design Library series.PA, USA: Elsevier; 2015. 604 p. ISBN: 9780323353991

[23]. Srisuwan Y, Srisaard M, Sittiwet C, Baimark Y, Narkkong N-A, Butiman C. Preparationand characterization and characterization of nanocomposite and nanoporous silk friboinfilms. Journal of Applied Sciences. 2008;8(12):22582264. DOI: 10.3923 /jas.2008.2258.2264

[24]. Wang L, Hu C, Shao L. The antimicrobial activity of nanoparticles: present situation and prospects for the future. Int J Nanomedicine. $2017 \mathrm{Feb}$ 14;12:1227-1249.Pubmed PMID: 28243086

[25]. Vilchis-Nestor AR, Sánchez-Mendieta V, Camacho-López MA, Gómez-Espinosa RM, Camacho-López MA, Arenas-Alatorre JA. Solventless synthesis and optical properties of $\mathrm{Au}$ and $\mathrm{Ag}$ nanoparticles using Camellia sinensis extract. Mater. Lett. 2008 Jun 30;62(17-18):3103-5.

[26]. Rosas-Piñón Y, Mejía A, Díaz-Ruiz G, Aguilar MI, Sánchez-Nieto S, RiveroCruz JF. Ethnobotanical survey and antibacterial activity of plants used in the Altiplane region of Mexico for the treatment of oral cavity infections. J Ethnopharmacol. 2012 Jun 14;141(3):860-5.Pubmed PMID: 22465591.

[27]. Frost \& Sullivan Market Insight. Does the Suture have a Future? [Internet]. 2002. Availablefrom

[28]. Srinivasulu K, Kumar ND. A review on properties of surgical sutures and applications in medical field. Int J Res Eng Technol. 2014;2(2):85-96.

[29]. Guzman M, Dille J, Godet S. Synthesis and antibacterial activity of silver nanoparticles against gram-positive and gram-negative bacteria. Nanomedicine: Nanotechnology, biology and medicine. 2012 Jan 1;8(1):37-45.

[30]. Dakal TC, Kumar A, Majumdar RS, Yadav V. Mechanistic basis of antimicrobial actions of silver nanoparticles. Front. microbiol. 2016 Nov 16;7:1831.

[31]. Wang L, Hu C, Shao L. The antimicrobial activity of nanoparticles: present situation and prospects for the future. Int J Nanomedicine. $2017 \mathrm{Feb}$ 14;12:1227-1249.Pubmed PMID: 28243086.

[32]. Vilchis-Nestor AR, Sánchez-Mendieta V, Camacho-López MA, Gómez-Espinosa RM, Camacho-López MA, Arenas-Alatorre JA. Solventless synthesis and optical properties of $\mathrm{Au}$ and $\mathrm{Ag}$ nanoparticles using Camellia sinensis extract. Mater. Lett. 2008 Jun 30;62(17-18):3103-5.

[33]. Rogelio J. Scougall-Vilchis, Raúl A. Morales-Luckie,Víctor Sánchez-Mendieta and Rafael López-Castańares.Antimicrobial Effect of Silk and Catgut Suture Threads Coated with Biogenic Silver Nanoparticles.Silver Nanoparticles: Fabrication, Characterization and Applications,2018:249-261.

[34]. Rai M, Shegokar R, editors. Metal nanoparticles in pharma. Springer International Publishing; 2017 Nov 14:493.

[35]. Tillotson GS, Theriault N. New and alternative approaches to tackling antibiotic resistance. F1000Prime Rep. 2013;5:51.

[36]. Richter K, Van den Driessche F, Coenye T. Innovative approaches to treat Staphylococcus aureus biofilm-related infections. Essays Biochem. $2017 \mathrm{Mar}$ 3;61(1):61-70.

[37]. Rajeshkumar S. Green synthesis of different sized antimicrobial silver nanoparticles using different parts of plants-A Review. Int. J. Chemtech Res. 2016;9(4):197-208.

[38]. Rajeshkumar S, Bharath LV. Mechanism of plant-mediated synthesis of silver nanoparticles - A review on biomolecules involved, characterisation and antibacterial activity. Chem Biol Interact. 2017 Aug 1;273:219-227.Pubmed PMID: 28647323

[39]. Santhoshkumar J, Rajeshkumar S, Venkat Kumar S. Phyto-assisted synthesis, characterization and applications of gold nanoparticles - A review. Biochem Biophys Rep. 2017 Jun 21;11:46-57.Pubmed PMID: 28955767.

[40]. Menon S, Rajeshkumar S, Kumar V. A review on biogenic synthesis of gold nanoparticles, characterization, and its applications. Resource-Efficient Technologies. 2017 Dec 1;3(4):516-27. 